\title{
Clinical manifestations of essential tremor
}

\author{
EDMUND CRITCHLEY
}

\author{
From the Royal Infirmary, Preston
}

SUMMARY A clinical study of 42 patients with essential tremor is presented. In the case of 12 patients the family history strongly suggested an autosomal dominant mode of transmission, in four the mode of inheritance was indeterminate, and the remaining 26 patients were sporadic cases without an established genetic basis. The tremor involved the upper extremities in 41 patients, the head in 25 , lower limbs in 15, and trunk in two. Seven patients showed involvement of speech. Variations were found in the speed and regularity of the tremor. Leg involvement took a variety of forms: (1) direct involvement by tremor; (2) a painful limp associated with forearm tremor; (3) associated dyskinetic movements; (4) ataxia; (5) foot clubbing; and (6) evidence of peroneal muscular atrophy. Several minor symptoms - hyperhidrosis, cramps, dyskinetic movements, and ataxia - were associated with essential tremor. Other features were linked phenotypically to the ataxias and system degenerations. Apart from minor alterations in tone, expression, and arm swing, features of Parkinsonism were notably absent.

Essential tremor has been recognized as an organic peculiarity of the nervous system, mimicking neurotic and neural disorders with equal facility. Many synonyms-for example, benign, hereditary, and senile tremor-describe its varied presentation. Dana (1887) regarded 'hereditary' tremor as a hitherto undescribed form of motor neurosis, and observed that it resembles to some extent the tremor of paralysis agitans, still more a simple neurasthenic tremor, and was not accompanied by paralysis or any other disturbance of nervous function. Others commented on its resemblance to hysteria (Antony and Rouvillois, 1899) and to multiple sclerosis (Bergamesco, 1907; Dromard, 1908), but many disordersnotably, anxiety neuroses, inebriety, druginduced tremors, diabetic tremors, chorea, and thyrotoxicosis-may be simulated by essential tremor.

Parkinson (1817) and Charcot (1876) distinguished between the tremors of paralysis agitans and the senile variant of essential tremor. Both types of tremor characteristically affect the upper limbs. The Parkinsonian tremor involves alternating activation of opposing groups of muscles along the axis of the limb, is present at rest and disappears with activity. That of essential tremor, regardless of age of onset, is seen predominantly in the distal parts of the upper limb (Poirier, 1970), is more or less rhythmical, either fine or coarse, with a rate of 4 to $12 \mathrm{~Hz}$. There is much variation. It is occasionally present at rest and inhibited by action, but is more usually decreased or absent at rest and present on voluntary increase in muscle tonus, as in holding a limb in a definite position (static, sustained-postural or attitude tremor) and in active movement (kinetic or intention tremor). It may be accentuated on approaching a goal in point-to-point movement (terminal tremor) (Davis and Kunkle, 1951). In its mildest form the tremor diathesis may be no more than a kind of exaggeration of physiological tremor (Kreiss, 1912) properly managed by explanation and reassurance (Davis and Kunkle, 1951), or it may be so severe as to require stereotactic thalamotomy (Bertrand, Hardy, Molina-Negro, and Martinez, 1969). With the discovery of biogenic transmitter pathways for pathological tremors the need for a fuller review of the clinical manifestations of essential tremor has become more interesting and more urgent.

\section{PRESENT STUDY}

The present study is based upon a personal series of 42 patients in North Lancashire. Originally a group of 16 patients was selected with sufficient disability to justify a crossover trial of amantadine hydrochloride in the treatment of tremor (Cox, Critchley, Schnieden, and Williams, 1971). This study was carried out in parallel with a clinical assessment of tremor in a group of Parkinsonism patients receiving 
Levodopa. Both groups were repeatedly examined and monitored by a battery of standardized performance tests and by serial tremor recordings using a Grass Parkinsonism transducer. The remaining 26 patients include three originally excluded from the therapeutic trial because their symptoms were so mild that therapy was considered unnecessary. Where possible, other affected members from the families of these unrelated propositi were examined and the findings used to substantiate the manifestations of the propositus; but owing to the diversity of background and origin of the patients - two were Pakistani, two Jewish, two Irish, and one of Polish extraction-no attempt was made to examine all family members.

There were 30 males and 12 females with an agerange from 16 to 72 years (average 49 years). These propositi were divided into three genetic groups:

GROUP I. FAMILIES WITH SECONDARY CASES AND ONE PARENT AFFECTED 12 cases; four of these involved three generations. The parents of one proband were first cousins and her father, two children, sister, and sister's daughter were affected.

GROUP II. FAMILIES WITH NO AFFECTED PARENT BUT SIBLINGS, PARENT'S SIBLINGS OR GRANDPARENTS AFFECTED Four cases: (1) half-sister with Parkinsonism; (2) uncle with Parkinsonism; (3) sibling with essential tremor; and (4) grandmother with Parkinsonism.

GROUP III. SOLITARY CASES 26 cases; including one adopted child. With two patients there was evidence of other genetically determined traits-namely, premature whitening of hair and clubbed feet.

Combining these three groups, the mean age of onset of symptoms was 35 years (Table 1).

\section{CLINICAL FINDINGS}

The clinical examination resembled that used for the examination of Parkinsonism patients. Tone was examined by passive movement of the neck and by passive movement about the wrists and elbows simultaneously, with and without reinforcement from synkinetic movement of the opposite arm. The tremor was observed at rest,

TABLE 1

AGE OF ONSET OF SYMPTOMS

\begin{tabular}{ccccccc}
\hline \multicolumn{7}{c}{ Onset of symptoms (by decade) } \\
$\begin{array}{c}0-9 \\
\text { (no.) }\end{array}$ & $\begin{array}{c}10-19 \\
(\text { no. })\end{array}$ & $\begin{array}{c}20-29 \\
(\text { no. })\end{array}$ & $\begin{array}{c}20-39 \\
\text { (no.) }\end{array}$ & $\begin{array}{c}40-49 \\
(\text { no. })\end{array}$ & $\begin{array}{c}50-59 \\
\text { (no.) }\end{array}$ & $\begin{array}{c}60+ \\
(\text { no. })\end{array}$ \\
\hline 2 & 7 & 7 & 7 & 8 & 5 & 6 \\
\hline
\end{tabular}

TABLE 2

CLINICAL SIGNS

\begin{tabular}{|c|c|c|c|c|}
\hline $\begin{array}{c}\text { Family history } \\
\text { Signs }\end{array}$ & $\begin{array}{c}\text { Group I } \\
(\text { parent }+)\end{array}$ & $\begin{array}{l}\text { Group II } \\
\text { (others) }\end{array}$ & $\begin{array}{l}\text { Group III } \\
\quad \text { (lone) }\end{array}$ & $\begin{array}{c}\text { Total } \\
\text { nos. }\end{array}$ \\
\hline No associated & 2 & 1 & 13 & 16 \\
\hline $\begin{array}{l}\text { Associated } \\
\text { Minimal }\end{array}$ & 2 & 0 & 4 & 6 \\
\hline $\begin{array}{l}\text { Parkinsonism } \\
\text { Associated and }\end{array}$ & 5 & 1 & 8 & 14 \\
\hline Parkinsonism & 3 & 2 & 1 & 6 \\
\hline Totals & 12 & 4 & 26 & 42 \\
\hline
\end{tabular}

with maintenance of the typical Parkinsonism posture, with the arms extended and with fingernose movement. Particular attention was also given to the presence of associated neuropathic traits. The findings were then classified to assess the presence of minimal signs of Parkinsonism and of associated traits (Table 2).

CHARACTERISTICS OF TREMOR Marshall (1962) established two different patterns of upper limb tremor for essential tremor. The majority of patients had tremors which described a smooth regular wave form, indistinguishable from tha: seen in Parkinsonism. The frequency of tremo $c$ followed the age pattern for physiological tremos when the duration was held constant. The other. $\overrightarrow{0}$ patients showed small irregularities in the pato tern and Bertrand et al. (1969a) demonstrated with photokinetic and electromyographic techniques that these incoordinated movements lacked many of the characteristics of tremor. The present series contains many examples of both the smooth and the irregular tremor forms but within each of these groups there are broad variations. Those with predominantly distal involvement, with striking digital tremor, were usually the more irregular, often with a terminal increment or a sustained-postural flap. When a gross and seemingly isolated irregular movement was made it took the form of a speedily executed rapid but faulty adjustment. In one individual it was possible to observe continuous sideways jerking of the right forearm and a rhythmic movement of the left forearm. Involvement of $\frac{D}{2}$ the whole limb was most common in those with a smoother more regular tremor of the Parkin- 0 sonism type. The speed of tremor was indepen- N dent of the wave form and both smooth and $\underset{\omega}{N}$ irregular tremors were in some instances fast (between 8 to $10 \mathrm{~Hz}$ ) and in others slow (though 
not usually below $5 \mathrm{~Hz}$ ). Fast tremors were more common than slow tremors in the ratio $3: 2$.

Much variation was observed in the response to cold, nervousness, stress, fatigue, and emotion. A fine task might result in an exaggeration of the tremor or, contrariwise, there might be an amplification of disability when lifting or carrying heavy objects. The tremor often varied according to the time of day-thus, I.B. found her tremor most incapacitating in the morning, not immediately on rising but when she came to wash and dress, and E.F. had no trouble during the day but stopped evening visits to his office to prepare ahead as fatigue made him dithery and he could no longer decipher his notes the next morning. For some patients the inability to socialize was particularly distressing, involving such functions as speaking in public, shaking hands, eating, drinking, or even holding a glass in a communal place. A 39 year old school teacher, A.H., complained that when meeting men at interviews they would 'take her wrongly' assuming that they were having a startling emotional effect upon her as they shook her hand. In such situations the relief afforded by alcohol is readily recognized, so much so that it has been loosely regarded as an invariable or even pathognomonic feature of essential tremor. In the present series 19 patients found the effect of small quantities of alcohol beneficial but six others did not. The men usually found spirits most helpful but it was not uncommon for a lady to say that two pints of beer or a glass of stout helped best of all.

Handwriting was often affected by the tremor and influenced by emotional factors. One patient showed micrographia, but typically the writing was large, untidy, and indecipherable. Some patients were able to write neatly provided they pressed harder so as to limit the size of the script and prevent sudden, jerky movements of the pen. Commonly they would avoid writing in public, putting things aside for signature until feeling particularly well. An art teacher, D.S., had to give up her employment because she was no longer able to draw a straight line or teach pen-lettering, and a pensioner, W.G., could not sign his book to draw his allowance.

PARTS OF BODY INVOLVED IN TREMOR Tremor of the upper extremities was seen in all patients but one (a mild case with titubation), was bilateral in 32 , confined to the right side in seven and to the left in two. Not infrequently other parts of the body were involved in tremor and responded to the same influences as did upper limb tremor. Titubation was seen in 25 patients, taking the form in most of a sideways movement, sometimes fine and rapid and sometimes slower and coarse; and on passive neck movement a little

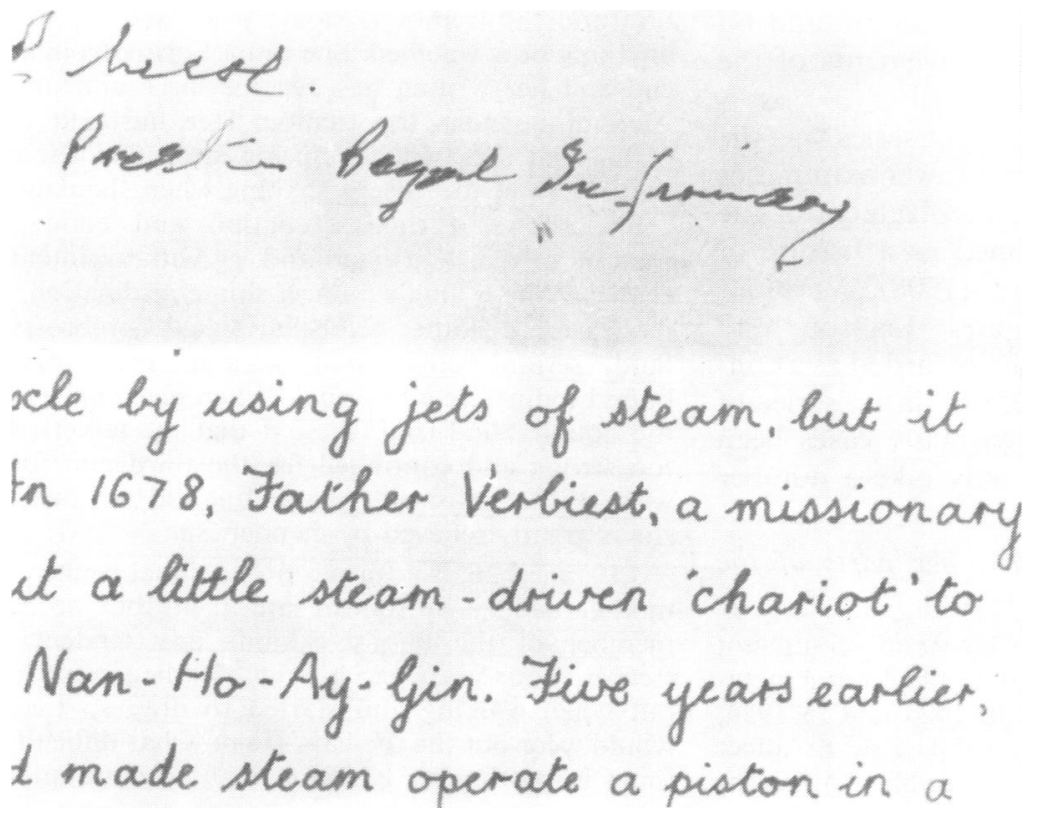

FIGURE. P.N., aged 70 , written with affected right hand, and (below) taught to write with left hand. 
cogwheel tremor was often felt. Four patients showed titubation with evidence of torsion spasm as described by Larsson and Sjögren (1960). Torsion spasm may begin with tremor and, in pedigrees with this disease, siblings and other relatives may have tremor as their only symptom. The evolution of torsion spasm was observed in one patient, F.K., a housewife aged 45 years. She had been under observation with a mild head tremor, which worsened with emotion and made her self-conscious on occasions, for $8 \frac{1}{2}$ years. Then her head started to draw to the left with exacerbations of tremor. This tendency lasted a few months and finally the tremor ceased but she continued to carry her head at an angle.

Several series (cf. Nettleship, 1911 ; van Bogaert and Savitsch, 1937) have included families with tremor-nystagmus. These patients probably belong to a subgroup of essential tremor. In the present series nystagmus was not seen though many patients displayed a slight hesitancy in reaching fixation and one, J.L., aged 26, who also had facial twitching, complained of slowness in focusing. A faciolabial tremor was present in only one patient but speech difficulties, related to tremor, were present in seven patients. One spoke with a thin whistle, another stammered, and five had slurring of speech; one patient claimed that amantadine loosened him up, helped his speech, and helped swallowing. Involvement of the trunk may also occur and was present in two patients, one of whom, A.B., a male aged 58, had a 10 year history of tremor with shaking of both hands, titubation, and on examination showed vertical movements of the musculature of the abdominal wall.

A striking finding in the present series was the occurrence of symptoms in the lower extremities in 15 out of the 42 patients. Involvement of the lower limbs, though mentioned as a feature of exceptional cases by Flatau (1908), Velander (1931), Critchley (1949), and Larsson and Sjögren (1960), has rarely been regarded as a concomitant of essential tremor, and in no series of unrelated individuals have so many cases been reported. This involvement may take a number of forms.

1. Spread of tremor from other parts of the body as described by Flatau (1908).

J.D., a 67 year old factory inspector, could not date the onset of his tremor but had had basal metabolic rate (BMR) estimations in 1924 and in 1944, and by 1959 his tremor was so bad as to affect shaving, writing, and eating in public. A recent exacerbation of the tremor was accompanied by heavy nocturnal sweating. His mother and sister also had tremors.

He had a masklike expression, no glabellar tap abnormality and an alternating strabismus. There was a moderately rapid, coarse, alternating tremor in both arms and at rest all four limbs were on the move. His head was not involved. Only with synkinesis was there any suggestion of a change in tone.

2. A variable, painful limp with mild symptoms of tremor elsewhere.

H.P., a male aged 45 years, had complained of an odd gait accompanied by pain behind the right ankle for more than 20 years. When walking his foot turns in and he had to reinforce his footwear with steel bars. The limp is lessened if he relaxes or has been resting, or takes a little alcohol, and is definitely worse in front of strangers. He discovered from an aunt that his father had had a similar limp, but no other member of the family is affected.

On examination, there were a few rapid movements of the right eye on looking to the right and with posturing he showed a mild, rapid tremor of the right arm. The tone was increased in the right arm with synkinesis, but the reflexes were physiologicat and symmetrical and cerebellar tests were well perf formed. His walk was at first ungainly with a tendence p. to stub his right foot but as he gained confidence in the examination the limp lessened and he showed nष difficulty walking on his toes, heels, or heel-to-toe.

3. Irregular dyskinetic movements associated. $\overrightarrow{0}$ with tremor.

J.W., aged 35 years, developed a tremor in her right hand in 1966. There has been a recent exacerbation and the tremor is worse when she is carrying anything or is watched. She cannot drink from a full cup and her writing has become large and untidy. Alcohol quietens the tremor. Her husband complains that she twitches during sleep and she says that her right foot keeps shaking when she dances.

She shows a mild titubation and compound tremors of the right hand and leg with an intention element. She is ataxic on heel-shin coordination, but there were no other cerebellar signs. Cerebrospinal fluid, serum copper oxidase and serum protein bound iodine are all normal. When given placebo in the double-blind trial, she felt that the tablets were too strong and continued for the third and fourth week on half dosage. Amantadine did not help but she is greatly relieved by mephenesin.

J.L., aged 26, is a former professional runner. His mother had Parkinsonism late in life but no other member of the family exhibits any tendency to tremor. Four years ago his right leg began to throw out when walking and started to drag so that he would wear out the toe-cap. He now has difficulty at times in putting his left foot to the ground and his 
balance has deteriorated. The tremor is more severe down the left side and affects his head, legs and hands. It is inconstant, for at home he manages well, dresses himself, and writes neatly, but in company he cannot. He could not take a tray of drinks into an assembled gathering unless he, himself, had had a few drinks beforehand.

$\mathrm{He}$ has a fine titubation and a variable, rapid tremor of his left arm and leg. His right arm is unaffected until he tries to light a match or build with blocks. His grip is strong. Tone is slightly increased in his neck and arms but the reflexes are not exaggerated and both plantar reflexes are flexor. His gait is clumsy with a widened base.

\section{Tremor of the upper limbs with an ataxic gait.}

J.W. and J.L. showed some ataxia. With the next patient this feature was so severe that it is probably advisable to regard him as having a double diagnosis of essential tremor and multiple sclerosis.

J.S., a clerk aged 56 years, had transient double vision when aged 21 years and a provisional diagnosis was made of multiple sclerosis. In action in 1944 he became paraplegic, was diagnosed as having shellshock but this was later amended to multiple sclerosis. He recovered completely. Five years ago (1965) he had further trouble with his left leg and hands and experienced difficulty in writing. His mother and maternal grandmother had essential tremor and he found that his own tremor was improved by taking spirits, though it often worsened two days later.

He had a fixed expression and turned slowly. There was a bilateral attitudinal tremor of the upper extremities without a terminal increment and without alterations in the tone or reflexes. He was helped by amantadine but after three months the effect wore off. The placebo had no effect but mephenesin has proved beneficial.

5. Other abnormalities which suggest a continuity with other central nervous system degenerations.

Two patients from the present series had clubbed feet-an association with essential tremor previously described by Kreiss (1912). Another patient had evidence of peroneal muscular atrophy in addition to essential tremor.

F.B., a male aged 53 years, attended the neurological clinic for many years with bilateral clubbing of his feet due to peroneal muscular atrophy. In 1968 he presented with transient ischaemic attacks due to vascular insufficiency and cervical spondylosis and six months ago started to stammer and shake his head and arms when excited. He complained that the muscles of the right leg vibrated at times and that he tended to stagger, raising the left foot higher than usual. There was no relevant family history.

He has a slight stammer, accompanied by tongue tremor. There is a tremor of the outstretched hands and a rapid titubation without nystagmus. The limb tremor is most marked in his right arm and tone is slightly increased by comparison with the left. His blood pressure is $180 / 100 \mathrm{mmHg}$. He has wasting below the knees, vasomotor changes, and clubbed feet. The ankle jerks are absent and the knee jerks obtained with difficulty.

ADDITIONAL FEATURES The association of hyperhidrosis and essential tremor, as seen in patient J.D., was originally described by Kreiss (1912). Another patient, D.S., complained of profuse sweating and knotty cramps. Her family history was particularly involved.

D.S., an art mistress aged 43 years, developed a tremor of the right hand when aged 14 and three years ago the tremor spread to involve the left hand. It worsens when she is harassed and she has difficulty holding a cup and saucer in company. Her inability to draw and teach calligraphy has already been commented upon. Sometimes the tremor will lesson if she takes alcohol. She once received thyroid extract and obtained a temporary diminution of the tremor thereby.

Her parents were first cousins and her father had cramps and tremor. All three children, now aged 20, 18, and 16 years, have tremors: the eldest started at 14 , the second had 'chorea' at 10 and has since had a tremor, and the third developed a tremor soon after her 16th birthday. A sister has cramps but no tremor, but her 23 year old daughter (the proband's niece) has had a tremor from the age of 16 years. All affected individuals complain of profuse sweating.

D.S. appears depressed, emotionally flat, and tends to obesity. The tremor is most marked when the arms are outstretched and it bears a resemblance to asterixis. There is no alteration in tone. Serum magnesium, copper oxidase, cholesterol, PBI, $\mathrm{pCO}_{2}$, and liver function tests are normal.

The electrocardiograms (ECGs) taken on those patients included in the therapeutic trial were analysed by Dr. Perez and Dr. Logan of the department of Cardiology, Victoria Hospital, Blackpool, for evidence suggestive of associated cardiomyopathies. No consistent abnormality was present and, apart from one ECG in a patient known to have ischaemic heart disease, they were within normal limits.

METABOLIC STUDIES There was no common pattern of metabolic disturbance. Glycosuria was seen in three patients. One had diabetes mellitus, another a lag storage glucose tolerance 
curve, and the third a low renal threshold. Three patients were hypertensive and five others had labile systolic readings. One patient, treated with amantadine, developed proptosis and lidlag. Her protein bound iodine (PBI) was elevated at $13.3 \mu \mathrm{g} / \mathrm{ml}$. At a lower dose of amantadine her clinical state improved and the PBI subsequently fell to $6 \cdot 7 \mu \mathrm{g} / \mathrm{ml}$. Many patients had had estimations made of their PBI and in some cases high normal values $(8-10 \mu \mathrm{g} / \mathrm{ml}$.) were observed but they remained euthyroid.

These patients, who represented a minority of the total series, formed so heterogeneous a group that it is reasonable to suppose that the metabolic disturbance was incidental, or if in any way causal, dependent upon the activation of a strong latent tendency. Nevertheless, in two patients the coexistence of an essential tremor and a metabolic disturbance presented diagnostic difficulties:

1. W.G., aged 72 years, had a long history of trembling beginning before 1939 and affecting both arms, particularly the right. In the past two years he has been unable to take tea in a café or to sign his name on official forms and has developed a mild dysarthria. He volunteered that the only time he gets relief is if he has two pints of beer, after which he feels champion.

His blood pressure was $170 / 100 \mathrm{mmHg}$ and had been at this level for many years. In 1967 he was found to have glycosuria in a diabetic detection drive and in 1970 showed a lag storage glucose tolerance curve. His PBI was $5 \cdot 3 \mu \mathrm{g} / \mathrm{ml}$. Benzhexol did not help and amantadine worsened the tremor. $\mathrm{He}$ had a digital tremor of an action and sustained-postural type without reflex or tone change.

2. G.H., aged 64 years, had been a diabetic receiving insulin for 20 years, had had two gastrectomy operations and was treated with streptomycin in 1959 for pulmonary tuberculosis. Eight months ago his hands started shaking. There was a family history of diabetes and also a family history, separate from this, of tremor affecting his mother and maternal grandmother.

He shakes his hand, head, and mouth and occasionally his right arm. He has difficulty writing and shaving and sometimes has to put things aside for signing until he is feeling particularly well. If he takes alcohol he finds the tremor is better.

He showed bilateral ptosis, an inexpressive face, a little cogwheel tremor in his neck and, with reinforcement, an alteration in tone in his arms. The tremor was rapid with brisk reflexes and without true rigidity or bradykinesia. The blood pressure was $170 / 100 \mathrm{mmHg}$. His writing was improved on amantadine $200 \mathrm{mg}$ daily and he was able to carry out his offices as a priest with less embarrassment.
THE PlaCe OF TREATMENT Caution must be properly exercised in attempting to treat a condition which may be lifelong and in which the ultimate prognosis qua incapacity is considerably better than it is in Parkinsonism; but not infrequently the patient finds that the tremor is seriously interfering with his life (Kelly, 1965). In childhood, school failure may result from an inability to write properly due to the tremor (Ford, 1966). Adults may develop neuroses-for example, being unable to have their hair cut in public (Blacker, Bertrand, Martinez, Hardy, and Molina-Negro, 1968; also F.W. from the present series)-or have to leave their occupation because of incapacity arising as a direct result of their tremor-A.S. could not continue in his post as airport comptroller as his tremor worsened whenever an aircraft landed awkwardly; a lorrydriver, F.R., experienced difficulty pulling the steering wheel round sharp corners and in fixing the ropes and tarpaulin over his load; and a toolmaker, R.F., retired prematurely at 56 years of age because he was unable to use a screwdriver on Two patients were invalided out of the arme $\bar{\phi} \omega$ forces, and several others, working as salesmem of or business executives, sought treatment because the tremor was damaging their prospects of pro motion.

The most successful drug for intermittent use in the control of tremor is mephenesin. Kell $\vec{\theta}$ claims that, provided the patient can tolerate $N$ mephenesin in a sufficiently large dose, the tremor can be suppressed in 70 to $80 \%$ of cases for about 20 to 30 minutes at a time. The two patients for whom this form of treatment seemed appropriate both responded well. For more prolonged control the results are less satisfactory. Fifteen out of 26 patients found amantadine beneficial as compared with five out of 14 who responded to placebo and six out of 12 who were helped by chlordiazepoxide. Anticholinergic drugs were of help in only four out of 10 patients and alcohol was helpful in 19 out of 25 . Neither Levodopa (used in two patients) nor tetrabenazine (four patients) was found to be of value.

RELATIONSHIP OF ESSENTIAL TREMOR TO PARKINSONISM The frequency with which the two conditions are confused is illustrated by Hoehn and Yahr's (1967) study of the natural history of Parkinsonism. From the total group of 856 patients they found it necessary to exclude 54 patients - 15 because of incorrect information or inaccurate diagnosis and 39 because they were 
found to have essential or familial tremor with 'none of the classical signs of Parkinsonism'. Thus approximately $4.5 \%$ of patients referred as having Parkinsonism had essential tremor. In the present series four patients came with a diagnosis of Parkinsonism, compared with 103 patients seen personally over the same period correctly diagnosed as having Parkinsonism. The percentage figure corresponds with that of Hoehn and Yahr; but, out of a total of 42 patients seen with essential tremor, less than $10 \%$ were incorrectly labelled as Parkinsonism. Most patients were referred for diagnosis and treatment, two were considered to have multiple sclerosis, three anxiety states, and one thyrotoxicosis. These observations contrast with the study of 14 cases of benign essential tremor (Davis and Kunkle, 1951), the majority of whom had previously received the diagnosis of paralysis agitans.

\section{DISCUSSION}

The evidence for an autosomal dominant form of essential tremor (Davis and Kunkle, 1951; Larsson and Sjögren, 1960) is conclusive and many of the patients in the present study conform to this mode of inheritance. Sporadic cases are well recognized and by no means rare (Marshall, 1962). Their interpretation is open to dispute. In 1949 Macdonald Critchley felt it probable that more than one type of inheritance was concerned but it could be that sporadic cases arise where the predisposition to essential tremor is inherited as a dominant gene and the degree of penetrance is variable; thus Jager and King (1955) found many instances of hereditary tremor which would have been overlooked on the basis of history taking. The hypothesis of a genetic predisposition or 'inferiority of the nervous system' (Kreiss, 1912) would explain how, in some cases, a subclinical metabolic or vascular derangement could result in an irreversible tremor diathesis by exploitation of an intrinsic defect, for example, through an impairment of a dampening mechanism concerned in the control of physiological tremor as suggested by Marshall (1962).

Advances in the histochemistry (Birkmayer and Hornykiewicz, 1961) and therapy of Parkinsonism have made the separation of essential tremor from Parkinsonism less dependent upon an arbitrary clinical differentiation as propounded by Hoehn and Yahr (1967), even though the histological basis of essential tremor is still unknown (Herskovits and Blackwood,
1969). A further longitudinal separation may be arrived at from the natural history of the two conditions. Essential tremor arises as an exaggeration of physiological tremor (Kreiss, 1912) with episodic increases in amplitude occurring against a background of tremor of the same frequency but of lower amplitude (Marshall, 1962). As the malady worsens, there is much variation in the regularity of the wave form and in the severity and spread of the tremor; thus patients may present different types of tremor, either concomitantly or in succession, as the disease progresses (Poirier, 1970). It is this syndromic variation which makes the experimental simulation of essential tremor so fallible.

Peripheral mechanisms concerned in the production of physiological tremor have been extensively studied and it is held that many forms of metabolic tremor result from activation of peripheral $\beta$-adrenergic receptors (Marsden, Foley, Owen, and McAllister, 1967). Activation of these receptors may account for the tremors of thyrotoxicosis, anxiety states, and hypertension; but adrenergic receptor blockade is not of consistent therapeutic value in the treatment of essential tremor. The same receptors are involved in hypoglycaemic tremor but their role in diabetic tremor-seen in a small percentage of diabetic subjects-is poorly understood. An alternative explanation, frequently advanced, is that this tremor arises as a result of the premature atherosclerosis of the diabetic subject, despite the evidence of Charcot (1876), Barker (1939), and Critchley (1956) that tremor is a rare manifestation of the ageing process, Furthermore, it is reasonable to assert that, apart from the condition of 'arteriosclerotic' Parkinsonism, in which atherosclerotic changes are seen in the central nervous system concurrently with cellular changes and enzymic depletion, it is parenchymatous, not arteriosclerotic, degeneration which results in tremor.

To many authors (cf. Davis and Kunkle, 1951; Jager and King, 1955) essential tremor is a monosymptomatic condition; but the more widely based series (Critchley, 1949; Larsson and Sjögren, 1960; and Bertrand et al., 1969b) agree in that 'the presence of associated neurological signs (e.g. spasmodic torticollis) in addition to tremor does not necessarily negate the diagnosis of essential tremor' (Blacker et al., 1968). The evidence presented by Larsson and Sjögren relates to a closed community-namely, a Swedish parish in which, with two exceptions, all 210 
cases could be traced back to four ancestral couples. Additional neurological symptoms were found in 17 out of 81 cases. They also observed rigidity of spasmus mobilis type which was inconstant and of relatively slight degree. In 16 cases the gait was stiff but there were no symptoms of akinesia or any tendency to pulsion. It is possible that in Larsson and Sjögren's somewhat inbred population the additional neuropathic features represented the chance association of genes, but additional neurological signs associated with essential tremor are also seen in random cases and Critchley (1949) found it necessary to refer to essential tremor and its clinical variants. In the present series particular attention was paid to minimal signs of Parkinsonism and to additional neurological factors. These signs were frequently observed. No patients, however, showed a positive glabellar tap phenomenon and no manifestations were more striking than those referred to by Larsson and Sjögren. Neither the signs of Parkinsonism nor the other neurological signs were more prevalent in the inherited or sporadic groups.

The relationship of the associated neurological signs seen in patients with essential tremor and the ataxias has been subject to much discussion, notably by Macdonald Critchley. Critchley and Greenfield (1948) held that in some cases essential tremor might represent a forme fruste of a presenile atrophy such as olivopontocerebellar atrophy. It is more probable that these conditions are the result of quite different genes, although the clinical (phenotypic) manifestations often show similarities or overlap.

I wish to thank Professor H. Schnieden and Dr. P. K. Thomas for advice in the preparation of the manuscript.

\section{REFERENCES}

Antony and Rouvillois (1899). Tremblement essentiel avec stigmates d'hystérie. Revue Neurologique, 7, 386.

Barker, L. F. (1939). Ageing from the point of view of the clinician. Problems of Ageing, pp. 717-742. Edited by E. V. Cowdry. Williams and Wilkins: Baltimore.

Bergamasco, I. (1907). Intorno ad un caso di tremore essenziale simulante in parte il quadro della sclerosi multipla. Rivista di Patologia Nervosa e Mentale, 12, 4-9.

Bertrand, C., Hardy, J., Molina-Negro, P., and Martinez, S. N. (1969a). Optimum physiological target for the arrest of tremor. Third Symposium on Parkinson's Disease, held at the Royal College of Surgeons of Edinburgh, pp. 251-259. Livingstone: Edinburgh.

Bertrand, C., Hardy, J., Molina-Negro, P., and Martinez, S. N. (1969b). Tremor of attitude. Confinia Neurologica, 31, $37-41$.
Birkmayer, W., and Hornykiewicz, O. (1961). Der L-3, 4-Dioxyphenylalanin (= DOPA)-Effekt bei der ParkinsonAkinese. Wiener Klinische Wochenschrift, 73, 787-788.

Blacker, H. M., Bertrand, C., Martinez, N., Hardy, J., and $Z$ Molina-Negro, P. (1968). Hypotonia accompanying the neurosurgical relief of essential tremor. Journal of Nervous and Mental Diseases, 147, 49-55.

Bogaert, L. van, and Savitsch, E. de (1937). Sur une maladie congénitale et hérédofamiliale comportant un tremble- $T$ ment rythmique de la tête, des globes oculaires, et des $\underset{\sim}{\mathscr{C}}$ membres supérieurs. Encéphale, 32, 113-139.

Charcot, J. M., cf. Bourneville, D. M. (1876). Du tremblement sénile. Progrès Mêdicine, 4, 815-816.

Cox, B., Critchley, E. M. R., Schnieden, H., and Williams, C. (1971). Some pharmacological actions of amantadine $\Rightarrow$ hydrochloride and its effects on experimental and clinical of tremor. Paper read at the International Symposium on $\bar{O}$ Tremor. Sarajevo, Yugoslavia.

Critchley, M., and Greenfield, J. G. (1948). Olivo-pontocerebellar atrophy. Brain, 71, 343-364.

Critchley, M. (1949). Observations on essential (heredofamilial) tremor. Brain, 72, 113-139.

Critchley, M. (1956). Neurologic changes in the aged. Journal of Chronic Diseases, 3, 459-477.

Dana, C. L. (1887). Hereditary tremor, a hitherto undescribed form of motor neurosis. American Journal of Medical Sciences, 94, 386-393.

Davis, C. H. Jr., and Kunkle, E. C. (1951). Benign essential (heredofamilial) tremor. Archives of Internal Medicine, 97, 808-816.

Dromard, G. (1908). Tremblement héréditaire rappelant celui de la sclérose en plaques. Encéphale, 3, 2me semestre, 45-5 $30 \omega$

Flatau, G. (1908). Ueber hereditären essentiellen Tremo\& Archiv für Psychiatrie und Nervenkrankheiten, vereinis of mit Zeitschrift für die gesamte Neurologie und Psychiatri 44, 306-340.

Ford, F. R. (1966). Diseases of the Nervous System in Infanc开 Childhood, and Adolescence, 5th edition, p. 296. Thoma§ Springfield, Ill.

Herskovits, E., and Blackwood, W. (1969). Essential (familią hereditary) tremor: a case report. Journal of Neurolog Neurosurgery, and Psychiatry, 32, 509-511.

Hoehn, M. M., and Yahr, M. D. (1967). Parkinsonism: onset, progression and mortality. Neurology (Minneap.), 17, $427-442$.

Jager, B. V., and King, T. (1955). Hereditary tremor. Archives of Internal Medicine, 95, 788-793

Kelly, R. (1965). Tremor. In Encyclopaedia of General Practice, vol. 6, pp. 210-216. Edited by G. F. Abercrombie and R. M. S. McConaghey. Butterworths: London.

Kreiss, Ph. (1912). Über hereditären Tremor. Deutsche Zeitschrift für Nervenheilkunde, 44, 111-123.

Larsson, T., and Sjögren, T. (1960). Essential tremor. A clinical and genetic population study. Acta Psychiatrica et Neurologica Scandinavica, 36, Suppl. 144.

Marsden, C. D., Foley, T. H., Owen, D. A. L., and McAllister, R. G. (1967). Peripheral $\beta$-adrenergic receptors concerned with tremor. Clinical Science, 33, 53-65.

Marshall, J. (1962). Observations on essential tremor. Journal of Neurology, Neurosurgery, and Psychiatry, 25, 122-125.

Nettleship, E. (1911). On some cases of hereditary nystagmus. Transactions of the Ophthalmological Society of the United Kingdom, 31, 159-202.

Parkinson, James (1817). An Essay on the Shaking Palsy. Whittingham and Rowland: London.

Poirier, L. J. (1970). Recent views on tremors and their treatment. In Modern Trends in Neurology, 5. Pp. 80-85. Edited $\sigma$ by D. Williams, Butterworths: London.

Velander, F. G. H. (1931). Arftlighetsstudier inom tvenne $\mathbb{O}$ släkter med hereditär tremor. Nordisk Medicinsk Tidskrift, స్ 3, 102-108. 